\title{
Giant coronary aneurysm in Kawasaki disease, utility of coronary computed tomography
}

\author{
Aneurisma coronario gigante en la enfermedad de Kawasaki, utilidad de la
Laura Díaz-Chirón ${ }^{1 *}$, Juan Calvo ${ }^{2}$, Helena Cigarrán ${ }^{2}$, César Morís ${ }^{1}$, and Cecilia Corros ${ }^{1}$
${ }^{1}$ Cardiology Department; ${ }^{2}$ Radiology Department, Hospital Universitario Central de Asturias, Oviedo, Asturias, Spain
}

A 14-year-old boy with a history of ostium secundum atrial septal defect, closed percutaneously, was admitted in our institution with a 5-day history of fever and generalized rash. Physical findings included pruritic maculopapular erythematous rash, fingers edema, conjunctival hyperemia, oropharynx bright red mucosa, and submandibular and axillary adenopathies. Transthoracic echocardiography (TTE) demonstrated dilation of coronary arteries. The right coronary (RCA) was dilated proximally $(7 \mathrm{~mm}$, Fig. $1 \mathrm{~A})$ as well as was the left main artery (LMA) (5 mm Fig. 1B). To improve characterization of findings, a coronary computed tomography (CT) (CT of 128 detectors was used with dual energy. A retrospective acquisition was performed with dose modulation. Atenolol intravenous $(5 \mathrm{ml})$ was administered) was performed confirming the presence of large coronary aneurysms predominantly in bifurcations areas (Fig. 1C). The LMA presented a giant aneurysm (14 mm $\times 12 \mathrm{~mm}$ ) (Fig. 1D), LAD exhibited aneurysms in proximal and middle third $(7.4 \mathrm{~mm} \times 4.5 \mathrm{~mm}$ and $6 \mathrm{~mm} \times 6 \mathrm{~mm}$, respectively) (Fig. 1E). Circumflex exhibited aneurysms in proximal segment $(6 \mathrm{~mm} \times 5 \mathrm{~mm})$ (Fig. 1F). RCA was diffusely dilated: $8.3 \mathrm{~mm} \times 8 \mathrm{~mm}$ proximal, $7 \mathrm{~mm} \times 6.6 \mathrm{~mm}$ in middle, and $5 \mathrm{~mm} \times 5 \mathrm{~mm}$ in distal third (Fig. 1G). Diagnosis of Kawasaki disease was made, and treatment with aspirin, anticoagulation, and immunoglobulins was started. TTE is being performed routinely with no changes in aneurysm dimensions.

Kawasaki disease is an acute self-limiting vascülitis of unknown etiology 1 . Coronary aneurysms are the main complication and the leading cause of long-ferm morbidity and mortality, especially giant aneurysms $(>8 \mathrm{~mm})^{1}$. For this reason, it is essential an early treatment; therefore, a prompt diagnosis is mandatory. ETT is a very useful technique to evaluate coronaries. However, CT is more sensitive than ETT detecting aneurysms and improving their characterization?

\section{Conflicts of interest}

All authors have no conflicts of interest to disclosure.

\section{Funding}

None.
Date of reception: 10-03-2019 33011 Oviedo, Asturias, España E-mail: lauradcs89@gmail.com BY-NC-ND license (http://creativecommons.org/licenses/by-nc-nd/4.0/).
Date of acceptance: 12-03-2019 DOI: 10.24875/ACME.M19000061
Available online: 02-10-2019 Arch Cardiol Mex (Eng). 2019;89(3):245-246
www.archivoscardiologia.com Arch Cardiol Mex (Eng). 2019;89(3):245-246
www.archivoscardiologia.com 

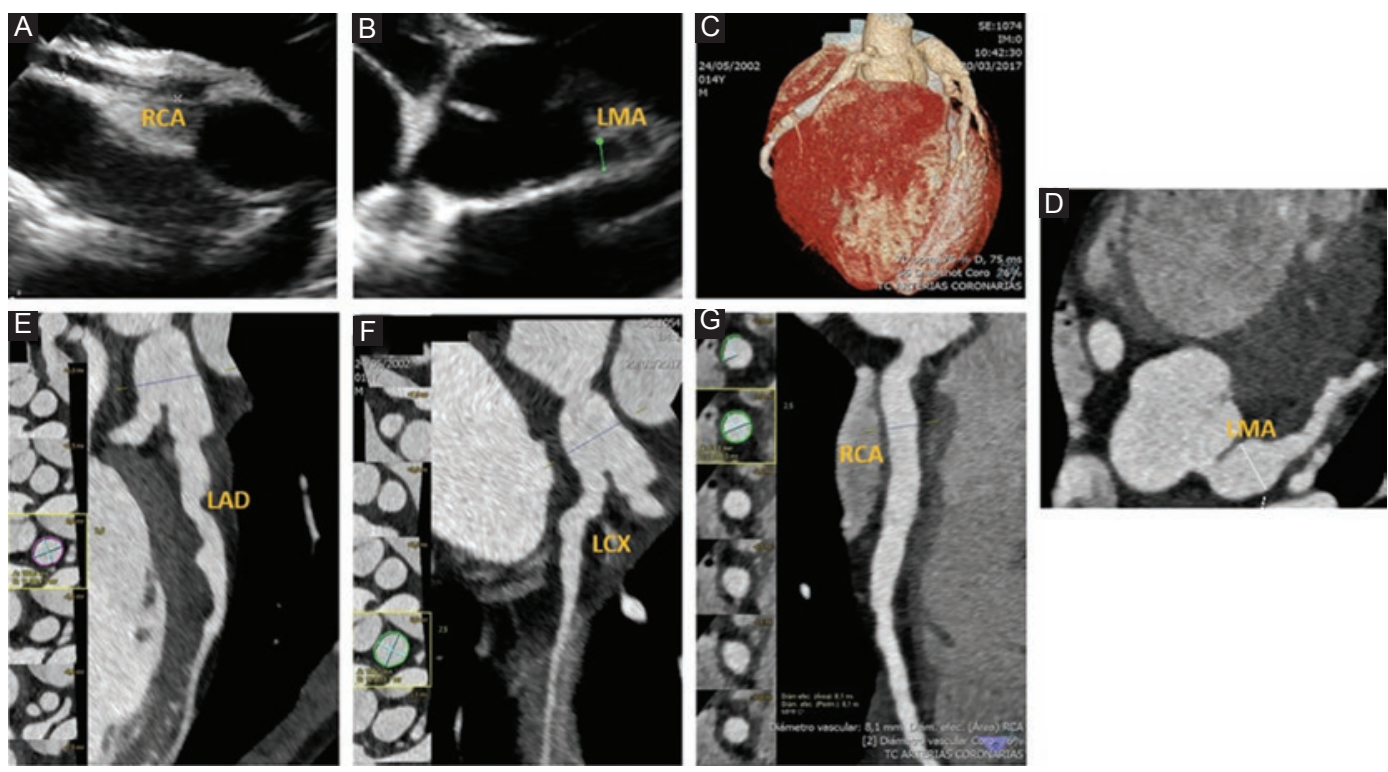

Figure 1. (A-G) Coronary aneurysms. (A) Transthoracic echocardiography (TTE) demonstrating dilation of the fight coronary artery; RCA: right coronary artery. (B) TTE demonstrating dilation of the left main artery; LMA: left main artery. (C-G) Coronary computed tomography confirming the presence of large coronary aneurysms; LAD: left anterior descending artery; LCX: left circumflex artery.

\section{Ethical disclosures}

Protection of human and animal subjects. The authors declare that no experiments were performed on humans or animals for this study.

Confidentiality of data. The authors declare that they have followed the protocols of their work center on the publication of patient data.

Right to privacy and informed consent. The authors have obtained the written informed consent of the patients or subjects mentioned in the article. Theocorresponding author is in possession of this document.

\section{References}

1. McCrindle BW, Rowley AH, Newburger JW et al. Diagnosis, treatment, and long-term management of Kawasaki disease: a scientific statement for health professionals from the American heart association. Circulation. 2017; 135:e927-99.

2. Duan $Y$, Wang $X$, Cheng $Z$, Wu D, Wu L. Application of prospective ECG-triggered dual-source CT coronary angiography for infants-and children with coronary artery aneurysms due to kawasaki disease. $\mathrm{Br} J$ Radiol. 2012;85:e1190-7. 